\title{
Electrification of the Gotibo Tribe: What Solutions for Sustainable Development?
}

Digbo Gogui Albert ${ }^{*}$

Assistant Professor, Sociologist Teacher-Researcher at the University Jean Lorougnon Guédé, Ivory Coast

*Corresponding author: Digbo Gogui Albert

Côte d'Ivoire has made access to electricity for the population as one of the components of the strategy to combat poverty in rural areas. Electrification is therefore considered a prerequisite for its economic and social development, thus contributing to the improvement of living conditions and human development. The introduction of this infrastructure in rural areas meets a dual interest: reducing the disparity observed between towns and villages and above all fighting poverty and social exclusion. Faced with their immediate needs, the populations of Gotibo are developing economic strategies and practices that are not always favorable to sustainable development. Despite the notable advances they have made thanks to electrification, the populations of the Gotibo tribe remain disadvantaged in terms of human capital formation. The article aims to develop new approaches on the theme of access for all to electricity services and the fight against poverty and social exclusion in Gotibo. This qualitative study was carried out in 2019 based on documentary research, direct observation and interviews. It emerges from this analysis that the social economy is the solution for a sustainable development of Gotibo.

Keywords: Gotibo tribe, rural electrification, poverty, social exclusion, sustainable development.

Copyright @ 2020: This is an open-access article distributed under the terms of the Creative Commons Attribution license which permits unrestricted use, distribution, and reproduction in any medium for non-commercial use (NonCommercial, or CC-BY-NC) provided the original author and source are credited.

\section{INTRODUCTION}

The Republic of Côte d'Ivoire has set itself an ambitious objective of promoting its development policy with a view to fostering the growth and diversification of its economy and enabling the wellbeing of its population [1].

Thus, thanks to a sustained energy policy from the 1970s onwards, it has developed electrical infrastructures which, to date, rank among the best in sub-Saharan Africa. In fact, the day after the tribe was connected to the national grid in 2000 , some villagers were able to increase their income. The villages have managed to make good progress in terms of life expectancy (considerable reduction in under-five mortality) by building health centers. These tribal villages have also made considerable progress in education (renovation of primary schools and creation of a modern college).

However, in recent years, village development has lagged or experienced a setback; over 90 percent $(90 \%)$ of the tribe's population still live in absolute poverty (our survey, 2019).
In a region where rurality remains the dominant human condition, the difficulty of young people and women to empower themselves is a factor of marginalization and exclusion [2]. Young people aspire to social and political status as much as to employment.

But at the current pace at which things are going, we are seeing an increase in the number of people living in poverty. Thus, the tribe needs to dramatically improve its types of economic growth in order to stem the impact of poverty and social exclusion and even reverse the trend.

Therefore, a sustained, broad and integrated approach promoting better entrepreneurial and job opportunities to promote increased economic growth at the level of women and young people will make it possible to fight against poverty and will lead to sustainable development at the level of the five (05) villages of Gotibo and throughout the Dignago SubPrefecture, and hence the country.

This article aims to show the importance of the social economy in the process of socio-economic 
development of Gotibo and especially in the reduction of poverty and social exclusion.

This article revolves around two major points: 1- A territorial approach to poverty and social exclusion and 2- The social economy, a solution for sustainable development.

\section{STUDY METHODOLOGY}

\section{Site and survey participants}

The study takes place in the Gotibo tribe of Dignago Sub-prefecture belonging to the Gôh region. Our investigation covered the five villages of the said tribe (Dribouo, Otéhoa, Gazahio, Beugréhoa and Bagasséhoa), electrified since 2000.

Thanks to the rapprochement of the modern administration with the citizens and rural populations, the Gotibo tribe was attached to the sub-prefecture of Dignago. This sub-prefecture, created on April 7, 2007, has an overall population of 35,000 inhabitants [3]. The Gotibo tribe which is our study area is eight kilometers from the Dignago sub-prefecture and covers an area of about sixteen square kilometers $(16 \mathrm{~km} 2)$ with a population estimated at more than half of the population of the sub-prefecture.
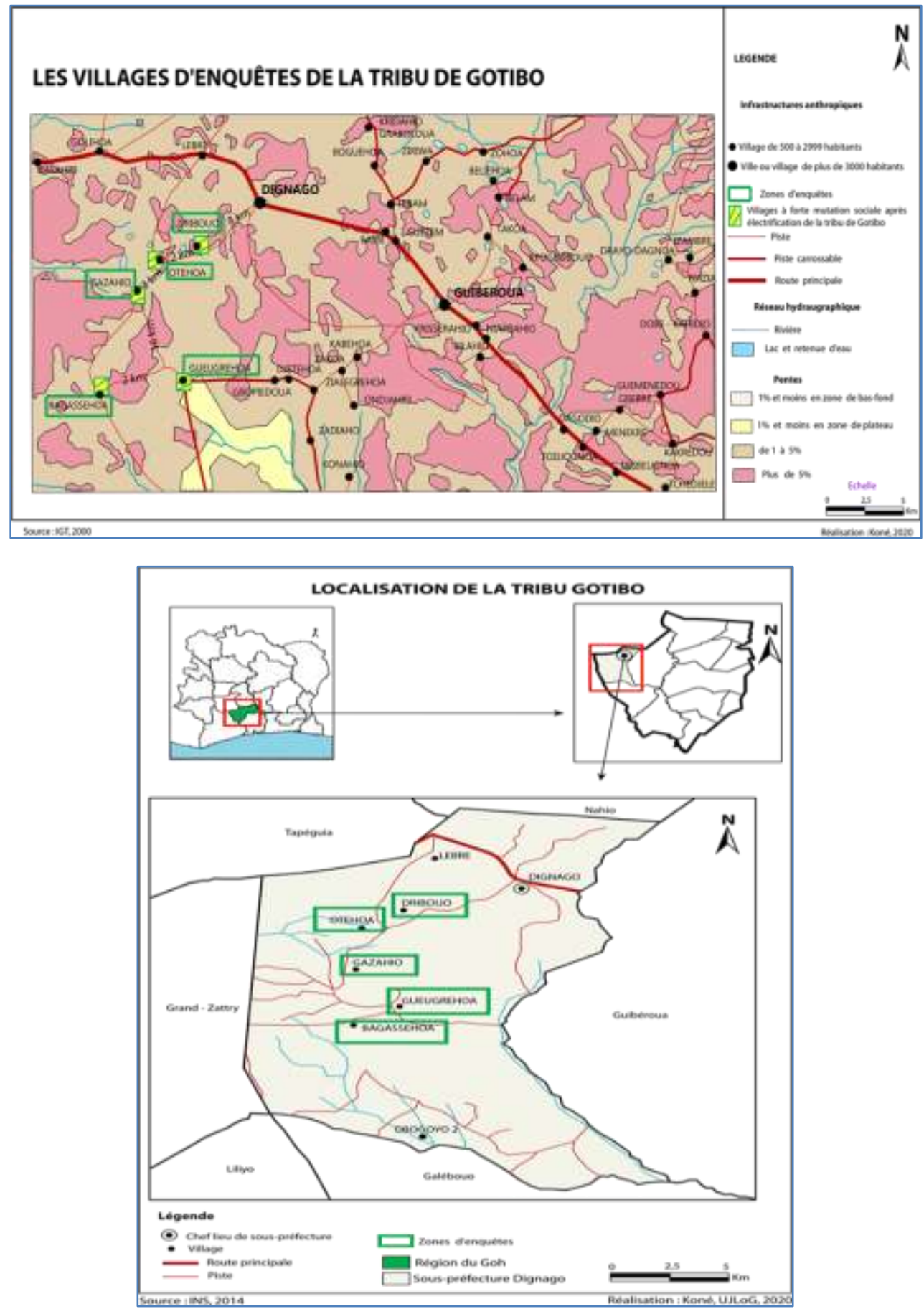
This study drew on information and opinions from all walks of life. However, our social scope has been limited for the most part to the population living in the villages of the tribe. The study was carried out with six categories of stakeholders:

- Women and young people;

- Agricultural producers, artisans and traders;

- Civil servants and state agents (teachers, teachers, nurses and midwives);

- Retired executives and heads of households;

- The chiefdoms of the various villages and the heads of immigrant communities;

- Members of Gotibo development associations and mutuals.

\section{Data collection techniques and tools}

The techniques evoke several mechanisms to achieve the expected results. As this study is part of a qualitative approach, the techniques we have used are: documentary research, direct observation and individual and group interviews.

The qualitative research techniques used in this research work mobilized the following tools: a reading grid, an observation grid and interview guides.

\section{Use of collected data}

The data collected underwent computer processing with Word 2013 and Sphinx 5.1 software. The information thus processed has made it possible to prepare this document.

\section{RESULTS AND DISCUSSUIN}

\section{A territorial approach to poverty and social exclusion}

\section{Insecurity and the exclusion of the poor}

Today, in the Gotibo world, not all villagers have access to electricity in villages that are electrified. In addition, the population's access to butane gas remains very limited due to the high cost of these products, the irregular supply of the market, particularly in gas, the prohibitive cost for the purchase of basic equipment and the limitation geographic supply circuits.

This situation leads the populations of Gotibo to resort more often to fuelwood as a source of energy for the satisfaction of their basic needs, which constitutes a threat both for the health of women, especially for the protection of the environment. And the balance of biodiversity.

Limited access to reliable and quality energy services severely hinders the economic and social development of the poor people of this tribe. Added to this is the fact that the pollution of air from traditional energy sources such as biomass particularly affects the health of the poor. This has an important influence on the quality of life of households and especially on that of women and children who devote a good part of their time to the tasks of collecting and transporting wood and water.

For several years, according to our interviewees, the Gotibo tribe was one of the most important economic zones in the former sub-prefecture of Guibéroua. The prizes won by the national progress cup, instituted by President Félix Houphouët Boigny with a view to motivating rural populations to achieve higher yields from export products, placed the Gotibo tribe at the forefront of the Guibéroua economies.

However, it should be noted that the tribe has experienced socio-political crises like Côte d'Ivoire in its history, which has resulted in weakening its position. With a once flourishing economy, the villages of Gotibo have always been a land of welcome for an immigrant population in search of jobs and well-being. The population of the Gotibo tribe, which was estimated, in 1998, at 14,157 inhabitants including 4,246 immigrants or $30 \%$ of the inhabitants of the tribe, rose in 2014 to 16,723 inhabitants with a foreign population of 6,021 or $36 \%$. mainly from Burkina-Faso [1].

The socio-political crises in Côte d'Ivoire, especially that of 2011, accentuated the tutoring crisis in the tribe. The increase in conflicts is an indicator of the deterioration of relations between actors regarding the use of land resources. Immigrants now see themselves as natives and forcibly occupy some plots of former guardians.

\section{Spread of poverty and social exclusion}

For a long time, development issues have remained synonymous with global growth, and analysts have often sought to find explanations for economic and social crises through phenomena linked to the real economy [4]. This dominant position of the economy in social life can only appear legitimate and defensible if the efforts deployed, in particular through social policies, effectively allow sustained economic growth which will be accompanied by a reduction in inequalities and cohesion. Social, argue these authors. This condition is far from true in the Gotibo tribe, according to our investigation.

In fact, the crisis that the country went through from the year 2000 significantly weakened the Ivorian economy and, consequently, that of the Gotibo tribe. The economy of the villages of Gotibo has suffered greatly from the degradation of basic production factors since the 2011 crisis. The post-election crisis and the fall in cocoa and rubber prices on the Ivorian market have worsened an already precarious economic situation. 
Cash crops (cocoa and rubber) on which the villagers, the Gotiwa, rely to improve their living conditions (connect or improve their electricity consumption) are experiencing a drastic drop in their selling price. For example, the farm gate purchase price per kilo of cocoa fluctuates between 300 and $400 \mathrm{f} \mathrm{cfa}$ (it rose to 750 in 2019), while that of rubber is between 250 and $300 \mathrm{f}$ cfa according to the respondents. Insecurity in this area has also greatly reduced the production, distribution and even the marketing of goods.

The particularly tense situation in the electricity sector and the low level of access of the populations to modern energy services are factors limiting development. The relative prosperity that the Gotibo tribe experienced through the production of coffee and cocoa does not seem to have lifted the peasants out of poverty. Indeed, the analysis of the development of the Gotiwa villages reveals poor social indicators, the low income of which was born from production and marketing difficulties both for the two products mentioned above and for other cash crops such as 'rubber tree.

In terms of production, the decline in productivity is largely due to the use of archaic cultivation methods. Agriculture is not mechanized, nor even irrigated.

Access of village populations to energy services (lighting, cooking, heating, refrigeration, audiovisual, transport, communication, etc.) by modern means is currently very limited. Indeed, the tribe's energy balance highlights the predominance of traditional biomass which represents $90 \%$ of consumption [1]. Firewood is the most used to meet domestic and artisanal energy needs. Meeting the basic needs of populations (food, health, housing, etc.) requires, for most of them, the use of various forms of energy. Their scarcity or too high cost contributes to the maintenance and increase of poverty, especially in the villages of the Gotibo tribe.

As a result, the inaccessibility of the poor to an efficient service is equivalent to the impossibility of ensuring the coverage of their basic needs under satisfactory conditions. What characterizes poverty is therefore, beyond the low consumption of electrical energy, the exclusion of the poor from the energy transition processes currently observed and the ineffectiveness of the energy policies implemented to take into account the concerns of these poor populations.

Since 2000, the year of the electrification of the Gotibo tribe, exclusions have multiplied, ranging from precariousness and marginalization to social exclusion or differentiation. The proliferation of the phenomenon of social exclusion and poverty shows the ineffectiveness of social policies in the field of energy. Also, the monetary approach to poverty reveals that for more than 15 years that the villages have been electrified, $90 \%$ of the population of Gotibo has lived below the poverty line. Local surveys on household living standards are the only source of information on social exclusion in the five (05) villages of our survey site. Poverty in its monetary approach affects some families or households more than others.

The effects of poverty, observed in these villages, must be mitigated by social policies that can constitute genuine social safety nets. However, reality shows that the poor and the excluded both live in a precarious situation and are both affected by uncertainty and / or scarce resources. In Gotibo, poverty is a sign of social fracture and an indication of the villagers' marginalization. The various surveys on the standard of living of households, which we have carried out, highlight an unseen spread of social exclusion. In recent years, exclusions have multiplied, ranging from insecurity and marginalization to gender exclusions.

\section{Low impact of electricity on economic and human development}

Investments in power infrastructure have long been justified on the grounds that they will lead to significant improvements in economic development. In addition to this, proponents of access to energy, in particular, have argued that its improvement will have a greater impact on human development [5].

Moreover, the optimism of officials and villagers that access to electricity will lead to the economic development of the Gotibo tribe is fundamental. Because, for the Gotiwa, as for the developers, electrification promotes an increase in income and, therefore, an improvement in the capacity of the population to use modern energies.

However, as we have found in the field of study, the empirical evidence regarding the impacts of electrification on economic and social development in the tribal villages is somewhat weak. These data do not reveal significant and generalizable impacts in the locality. Moreover, when impacts have been observed, they are for the benefit of the financially well-off. Therefore, access to electricity is an insufficient condition to generate substantial economic gains.

It seems that the mere provision of electricity will not lead to the forms of economic development that are so much expected and needed [6]. Indeed, in Ivory Coast in general and in the Gotibo tribe in particular, investment aimed at increasing access to electricity has generally not been accompanied by policies stimulating economic development. The impact of access to electricity on household income diversification is limited if households do not gain better access to markets through improved road networks. 
Rather, efforts to improve access to electricity should be part of general development policies. In this regard, some authors have underlined the need to ensure that efforts to promote access to energy are part of the general context of energy transition, which links energy to thermal purposes, electricity for lighting and electricity for national industry [7]. According to this conception, to remedy poverty, at the same time, it is necessary to remedy the excessively reduced production capacity of rural Africa, because the inaccessibility of the poor to an efficient service is equivalent to the impossibility of ensuring coverage. Of their basic needs under satisfactory conditions.

Thus, the energy consumption habits of poor households, and especially poor households of the Gotibo tribe, show how much these poor households devote a greater portion of their income and time to meeting their energy needs than wealthy households who generally consume more energy in total [8]. This is because everyone needs a minimum amount of energy to survive. Poor households are also often forced using less efficient fuels and appliances than the wealthy, so they often have to spend more time and money meeting their most basic energy needs.

Regarding the development of Gotibo, in recent years, the villages of the tribe have developed a new approach to rural policy motivated by various factors. First, it is increasingly recognized that while agriculture remains important to the Gotiwa and is the major use of land, it has become a minor source of income and rural jobs in the tribe. Agriculture continues to increase the value of production but with less population and more capital.

Here we assert that electricity plays a primary role in access to energy, as it provides a wide range of energy services. However, efforts to promote access to energy have often been focused exclusively on ensuring access to electricity. This resulted, among other things, in a binary vision of access to energy in the villages of Dribouo, Otéhoa, Gazahio, Beugréhoa and Bagasséhoa, a vision according to which the populations are either "connected" or "not connected" [9].

Energy access policies have often focused only on connecting households. This gave rise to a simplistic view of access to energy. While the impact of electrification on household energy poverty is clearly demonstrated, the data regarding the economic impacts of electrification are much more ambiguous. The findings regarding the impacts on the development of small businesses, the diversification of livelihoods and household income are contradictory in our field of study. Our survey reveals that only a few households use electricity for productive, for economic purposes. So these are a few small business owners who use electric lighting to extend their working hours. These include hairdressing, sewing, maquis-bars, shops, etc.
It should be noted that few households in these tribal villages use electricity for productive purposes. We observe that the effects of rural electrification on economic development are limited. Therefore, efforts to fight poverty and social exclusion must go far beyond simple access to electricity.

Electrification is therefore an economically complex challenge to overcome. With $70 \%$ of the population living on less than two dollars a day, market potential is limited in the five villages in our study area (our survey, 2019).

\section{Social economy, a solution for sustainable development}

The dynamics of the rural economy require the creation of economic opportunities around promising sectors in order to provide a satisfactory income strengthening the purchasing power of rural populations. This dynamic should not be limited to agriculture alone because with the socio-economic changes and mutations marking the landscape of the Gotibo tribe, it is appropriate to promote the development of synergies with other sectors that provide wealth and resources. 'Jobs to revitalize and develop the local economy.

When rural people have access to electricity in their homes, they use it primarily for lighting, entertainment, and cooling. The results obtained from the survey are a perfect illustration of this. Observations of economic impacts present serious challenges to efforts to alleviate poverty in the tribe of our research field.

\section{Human capital and the fight against poverty and social exclusion}

The development of human capital is both an essential tool for ensuring sustained economic growth and combating poverty and social exclusion, and is also of paramount importance in itself. Indeed, as $\mathbf{M}$. Hussain, S. Moyo and T. Oshikoya underline, in electrified rural areas, a close correlation exists between investment in human capital and the fight against poverty [10].

In the Gotibo tribe, the fight against poverty and social exclusion will need a sustained, broad and integrated approach that promotes better employment and entrepreneurship opportunities to facilitate economic growth and sustainable development at the level of tribal villages. This approach will also require investments in the development of human capital.

Today, most African economies are distinguished by their factor endowments, including the availability of unskilled labor and natural resources. To move up the value chain and achieve economies geared towards efficiency and innovation, which are essential for stronger and sustainable growth, continuous 
investments with a high impact on human development are essential [11]. Indeed, these authors argue that to ensure sustainable and inclusive growth in a rapidly changing continent, this is the case for the five (05) villages of Gotibo, innovative solutions and efficient investments in the development of human capital are necessary.

The arguments for investing in human capital lie in the material and non-material benefits it brings. Broadly speaking, these benefits can be grouped into three closely related categories: direct benefits, indirect benefits, and general economic growth spillovers. Controlling poverty and vulnerability is an essential condition for the establishment of pro-poor growth, especially in the villages of our study site which have à high number of poor people.

As some authors argue, social protection is not only a cost, it is also an investment that the community cannot afford to do without. Its economic and social return is very high, not only because it meets the objectives of social policy and the concern for equality, but also because it promotes growth and the reduction of poverty in its many aspects [12].

The participation of the poor in the growth process as actors is beneficial for themselves as well as for the local and even national economy. Thus, social protection helps to expand access to public services and increase investment in human capital, especially in health and education, which will help increase productivity and make it easier to, for the poor, the exercise of a remunerated activity.

Studies in South Africa and Latin America repeatedly show marked improvement in health and education outcomes, especially following the implementation of cash transfer programs, whether subject or not. Conditions and social measures concerning health [13].

\section{The benefits of human capital through social programs}

It is recognized that human capital plays a determining role in economic growth. On the other hand, we must understand the multidimensional nature of this concept. In fact, the spinoffs linked to investments made in increasing human capital are normally reflected not only in terms of economic growth, but also in terms of the general well-being of populations (social cohesion and other factors such as the increase in social participation, reduction of social exclusion), etc. So increasing human capital has positive effects, regardless of age. These effects have been found to be even greater when this investment is made in the early years of childhood.
It is therefore for this reason that a large part of social programs aimed at increasing this capital must target children and young people and seek to intervene mainly in the field of education. As put forward by the OECD [14] "We can induce some of the effects of training on health and social behavior by promoting habits, characteristics and attitudes conducive to job creation, productivity, personal well-being, positive temporal choices and self-discipline. Some of these characteristics as well as the innate skills and strengths are acquired outside formal education, but are closely linked to school ".

Market failures in the agricultural commodities on which the income of the Gotibo tribe villages is mainly based should often open the door to more effective investments in poverty. Thus, in the presence of certain types of market inefficiencies and despite the possibility of savings, the poor proved unable to take advantage profitable opportunities that electric power offers them due to the lack of operational capacity.

They therefore remain captive in low productivity sectors of the economy, even when productive opportunities remain untapped, since they are unable to innovate. Therefore, investments in the poor can not only increase their ability to benefit from more profitable investments, but also reduce inequalities and inefficiencies. The people of Gotibo must therefore develop and adopt reform programs that best suit their context, because there is no one-size-fitsall solution. As a result, the development projects to be selected must be based on a careful analysis of local needs and challenges.

To do this, the following recommendations apply to the Gotibo tribe villages considered by the study at an unplanned level. These are villages that do not have adequate social project programs and have no specific plan to establish such a local system. Thus these recommendations are presented as follows:

- Design and implement a social development policy that makes it possible to clearly distribute the institutional and political responsibilities of the villages. The strategy here should serve to solid political and financial support for the villages.

- Define beneficiary targeting methods, payment terms and a rigorous monitoring system. It is therefore a matter of creating the administrative tools necessary for the smooth running of social and economic development.

- Develop key social action programs based on an in-depth analysis of the needs of the villages of the tribe to regularly support people suffering from extreme poverty and according to the needs of poor and vulnerable households. 


\section{Technology, an advantage for Gotiwa villages}

Traditional or village techniques have always existed. Good or imperfect, they are the fruit of long experience, adapted to local conditions, some remarkably developed and capable of evolution.

In the villages in our study, these are sets of traditional processes and methods for performing a number of tasks. They concern the dewatering of water, the "processing" of food, crafts, agriculture. However, modern techniques reduce fatigue and enhance safety at work. They seek to replace human strength with another energy and save time [15].

However, it is possible to seize certain opportunities to promote inclusive development in the five villages of Gotibo. Technology opens up opportunities by reaching the most vulnerable people. A sense of innovation and entrepreneurship can also help lift people out of poverty and exclusion.

To do this, we have to initiate Household Education, which is aimed at a larger fraction of the female population, whose social and economic role is recognized in the villages. Homework training for young peasant women must be developed. Reducing women's fatigue, improving rural housing and increasing family income are imperative. The new problems created by the rural exodus, the remoteness of generations and the payment of electricity bills must be solved.

In the village, the young women were unable to learn the skills. They are helpless in the face of an economy that forces them to buy products that the family does not have. Through appropriate, original formulas (evening classes, for example) home education must take on a social dimension, because currently the needs of families have become considerably standardized as well as the means used to satisfy them.

If certain problems are still linked to basic needs: finding accommodation, food, clothing, raising children, preserving health, and paying electricity bills, the Family Social Economy must broaden its research to include difficulties due to environment, technological development, relations between generations and between social groups [15]

In terms of agricultural production: analysis of the situation reveals that cultivation practices as a whole, far from helping to curb the negative effects of natural constraints, contribute to the aggravation of this situation of impoverishment. In addition, producers' strategies rarely integrate changes in techniques and internal and external markets, except in the case of a few export crops (Ministry of Planning and Development, 2004). In an increasingly open economic context, this traditional agriculture in Gotibo will not be able to withstand competition and position itself on the international market.

Therefore, the increase, diversification and intensification of agricultural production in the area imperatively require qualitative transformations at the level of the production apparatus, at the level of the behavior of actors and at the level of the socioeconomic environment. This is why the following priority actions should be considered:

- advisory support to producers and research / development;

- agricultural hydraulics;

- the development of hydro-agricultural facilities with priority given to the development of lowlands in order to intensify small-scale (electric) irrigation;

- $\quad$ promotion of promising sectors;

- the development of agro-industrial processing and the promotion of the marketing of agricultural products;

- he development of agricultural mechanization;

Rural households are further hampered by the charges associated with connecting electricity and paying monthly bills. To do this, it is important to put in place strategies that make the use of electricity profitable by electric irrigation for agriculture.

To make rural electrification projects profitable in a context of poverty reduction, it is necessary to consider an approach for the adoption of electricity in rural areas which must operate in an approach aimed at promoting the use of electricity among households with more modest means.

Lowlands and rivers constitute a considerable potential for agricultural development. However, this water is not used in an optimal way to promote and secure agricultural production through irrigation and limit the dependence of rainfed crops on climatic hazards [16, 17]. Hydro-agricultural developments in the tribe are still almost non-existent in relation to the potential offered by the rivers of the locality and in relation to the need to stabilize production to ensure the food security of the populations and reduce poverty, even 'social exclusion.

\section{CONCLUSION}

It appears from this study that the populations of Gotibo live under the weight of poverty and exclusion for some. In fact, in terms of agricultural production, analysis of the situation reveals that cultivation practices as a whole contribute to the aggravation of this situation of socioeconomic precariousness in this locality.

However, it is possible to seize certain opportunities to promote inclusive development in the five villages of Gotibo. Indeed, it is accepted that 
human capital plays a determining role in economic growth, which could considerably reduce the poverty of the populations of our study area. For, the participation of the poor in the growth process as actors is beneficial not only for themselves but for the villages of the Gotibo tribe and even beyond.

This study shows the need for the involvement of political and administrative authorities and executives for a better use of electricity in the tribe in order to improve the frameworks and the living conditions of the populations thus reducing poverty and social exclusion in the tribe. The villages surveyed.

\section{REFERENCES}

1. Digbo GA. A study of the social implications of the rural electrification of the Gotibo tribe in the S / $\mathrm{P}$ of Dignago (Gagnoa), Unique PhD Thesis, Félix Houphouët Boigny University, Abidjan; 2014.

2. Clara A. Young rural Sahelians, between exclusion and integration, in Contemporary Africa. 2016; 259: $133-136$

3. RGPH. Recensement Général de la Population et de l'Habitat.2014.

4. Fatima ARIB and Mustapha ZIKY. Innovative practices in the fight against poverty and exclusion: Case of the National Initiative for Human Development (INDH) in Morocco 12th Meeting of the Inter-University Network of Social and Solidarity Economy - Nancy. 2012.

5. Morrissey J. The Energy Challenge in Sub-Saharan Africa: A Guide for Advocates and Policy Makers. Addressing Energy Poverty, Oxfam America Ed. 2017.

6. Haughton $\mathbf{J}$ and Khandker SR. Handbook on poverty and inequality, World Bank, Washington DC, 2009b ; 20433
7. Sokona $\mathrm{Y}$ and Jean Philippe T. Energy and the fight against poverty, a debate other than that of renewable energies, in Les cahiers de GLOBAL CHANCE. 2002; 15.

8. Bacon R. Energy Expenditures of Low-Income Households: Data from Africa and Asia, Working Paper No. 54929, vol1, The World Region; 2010.

9. Practical Action. Poor People's Energy Outlook: Key Energy Messages for Poverty Reduction. Rugby, UK: Practical Action. 2014.

10. Hussain MN, SS. Moyo TW. Oshikoya. Human capital and the fight against poverty, Emerging Africa, Paris, 2000: 2

11. MURARA J. One Billion Opportunities: Developing Human Capital for Inclusive Growth in Africa, AfDB Strategy for Human Capital Development. 2011; 2012-2016.

12. Sabates-Wheeler and Haddad, 2005; Krech. Social Protection, Poverty Reduction and Pro-Poor Growth, in OECD Development Review. 2007; 2008/4 (9): 37- 63.

13. OECD. Research Notes, under the title Promoting Pro-Poor Growth: Social Protection, Paris; 2009.

14. OECD. The Well-Being of Nations: The Role of Human and Social Capital: OECD Center for Educational Research and Innovation; 2001.

15. Lesteven A. The family social economy in rural development Scientific and technical education collection, 14, UNESCO, Paris; 1985.

16. Roger Blein. The agricultural potential of West Africa (ECOWAS), IRAM. 2008; 44.

17. Blein R. "Elements of analysis on the new contexts and challenges of food security in the Sahel and West Africa". Preparatory document for the review of the food aid charter; Food crisis prevention network; CSAO-CILSS; 2007. 